Recebido em 11/2013. Aceito para publicação em 08/2014.

\title{
AVALIAÇÃO DE CITOCINAS NA FIBROSE HEPÁTICA INDUZIDA EM RATOS PELA LIGADURA DO DUCTO BILIAR
}

\author{
ASSESSMENT OF CYTOKINES IN LIVER FIBROSIS INDUCED IN RATS BY BILE DUCT \\ LIGATION
}

\author{
Juliana Saraiva Freitas ${ }^{1}$ \\ Amanda Birindeli Alkmin ${ }^{1}$ \\ Luciana Barros Sant'Anna ${ }^{2}$ \\ Maria Angélica Gargione Cardoso ${ }^{3}$
}

Resumo: A fibrose hepática é uma doença causada por uma grande variedade de doenças crônicas que afetam o fígado após diferentes agressões, cujo único tratamento é o transplante de fígado. A patogênese da fibrose engloba uma complexa interação entre as células e a matriz extracelular do tecido hepático, interações estas mediadas por citocinas que modulam a progressão da fibrose. O objetivo do trabalho foi analisar quantitativamente o perfil de citocinas pró-inflamatórias (IL-6 e TNF- $\alpha$ ) e anti-inflamatória (IL-10) no fígado de ratos, com diferentes graus de fibrose, induzida pela ligadura do ducto biliar (LDB). Vinte ratos foram submetidos ao procedimento da LDB e eutanasiados após 2, 4 e 6 semanas da indução da fibrose para a remoção do fígado e quantificação das citocinas pró e anti-inflamatórias pelo método de ELISA sanduíche. Foi observado o aumento na concentração de todas as citocinas após 4 semanas da $L D B$ e diminuição dessas concentrações na $6^{a}$ semana. Dentre as citocinas pró-inflamatórias, o TNF- $\alpha$ mostrou aumento e diminuição estatisticamente significantes, respectivamente, na $4^{\underline{a}} e$ 6a semana, quando comparado a IL-6, a qual não apresentou significância estatística em nenhuma semana após a LDB. A IL-10, mostrou-se, significativamente, elevada na $4^{a}$ semana, seguida de uma diminuição moderada na $6^{\underline{a}}$ semana. Esses resultados indicam que o TNF é a principal citocina na progessão da fibrose biliar, principalmente, durante sua fase intermediária. Ao mesmo tempo, a lL-10 atua nessa fase, limitando a produção da citocina pró-inflamatória TNF- $\alpha$, na tentativa de um controle endógeno da progressão da doença.

Palavras-chave: fibrose hepática; ligadura do ducto biliar; citocinas; ELISA sanduíche.

Abstract: Hepatic fibrosis is a disease caused by a wide variety of chronic diseases that affect the liver after different insults, and the only treatment is liver transplantation. The pathogenesis of liver fibrosis involves complex interaction between cells and the extracellular matrix of the liver tissue, which is mediated by cytokines that modulate the progression of fibrosis. The aim of this study was to quantitatively analyze the profile of proinflammatory (IL-6 and TNF- $\alpha$ ) and anti-inflammatory (IL-10) cytokines in the liver of rats with different degrees of fibrosis induced by bile duct ligation (BDL). Twenty rats were subjected to BDL procedure and euthanized after 2 , 4 , and 6 weeks of fibrosis induction for removal of liver and quantification of cytokines by sandwich ELISA method. After 4 weeks, an increase of all cytokines was observed, and after 6 weeks, all these cytokines were reduced. Among the pro-inflammatory cytokines, the TNF- $\alpha$ showed a statistically significant increase and decrease, respectively on the fourth and sixth week, when compared to IL-6, which was not statistically significant in any week after BDL. The IL-10 was significantly elevated on the fourth week, followed by a moderate decrease on week six. These results indicate that TNF- $\alpha$ is the main cytokine in biliary fibrosis progression mainly in the intermediate stage. In addition, the IL-10 acts at this stage by limiting the production of the pro-inflammatory cytokine TNF- $\alpha$ in an attempt of an endogenous control of the disease progression.

Keywords: hepatic fibrosis; bile duct ligation; cytokines; sandwich ELISA.

\footnotetext{
${ }^{1}$ Graduada em Biomedicina - Universidade do Vale do Paraíba - Univap, Brasil. E-mails: jully_sjc_2006@hotmail.com; amanda_berindelli@hotmail.com.

2 Doutora em Biologia Buco Dental Universidade Estadual de Campinas - Unicamp, Brasil. E-mail: lucianabsa@gmail.com.

${ }^{3}$ Doutora em Microbiologia (Biologia Molecular) - Universidade de São Paulo - USP, Brasil e Docente da Univap. E-mail: magc.farm@gmail.com.
}

Revista Univap - revista.univap.br

São José dos Campos-SP-Brasil, v. 20, n. 36, dez.2014. ISSN 2237-1753 


\section{INTRODUÇÃO}

A fibrose hepática é uma doença causada por uma grande variedade de doenças crônicas que afetam o fígado após diferentes agressões, dentre elas: infecção viral (hepatite B e C), alcoolismo, doenças auto-imunes, desordens metabólicas, tóxicas ou biliares, como as colestases causadas por cálculos biliares ou compressão do ducto biliar por tumores (LI; CRAWFORD, 2004). Após sucessivas agressões, o fígado sofre um processo de inflamação crônica e remodelação tecidual, que tem como principal característica o acúmulo de proteínas da matriz extracelular, decorrente do desequilíbrio entre síntese e degradação de seus componentes, principalmente o colágeno tipo I e III, o que modifica a arquitetura do parênquima hepático por meio da formação de septos fibróticos, que é o tecido cicatricial (BATALLER; BRENNER, 2005; HENDERSON; FORBES, 2008).

A fibrose induzida por Ligadura do Ducto Biliar (LDB) gera um estresse biomecânico no epitélio biliar, desencadeando uma intensa proliferação compensatória de suas células, com consequente expansão dos ductos biliares. Após essa fase mitogênica epitelial, a obstrução crônica das vias biliares causa uma grande ativação de miofibroblastos na região periductal e, finalmente, resulta em fibrose biliar (EZURE et al., 2000). Se não tratada adequadamente e a tempo, a fibrose progride e os septos fibróticos começam a envolver nódulos de hepatócitos em regeneração, caracterizando a cirrose hepática, que é o estágio final da doença (BATALLER; BRENNER, 2005; HENDERSON; FORBES, 2008). Os pacientes com cirrose têm um elevado risco de desenvolver hipertensão portal, falha irreversível do fígado ou carcinoma hepatocelular, sendo este o $5^{\circ}$ câncer mais frequente no mundo e a $3^{\mathrm{a}}$ causa de morte por câncer (SCHUTTE et al., 2009). No Brasil, durante os anos de 2001 e 2010, a cirrose foi a principal causa, não só de hospitalização, mas também a oitava causa de morte. Além disso, a carga de doenças do fígado é não apenas significativa, mas progressiva, pelo menos em termos de internações e mortalidade (NADER et al., 2014).

A patogênese da fibrose hepática engloba uma complexa interação entre as células e a matriz extracelular do tecido hepático (BATALLER; BRENNER, 2005). Diversos estudos têm demonstrado que a célula-chave na produção da fibrose no fígado é a célula estrelada de Ito, situada no espaço de Disse, que é o local que separa os capilares sinusóides dos hepatócitos. Essa célula é o principal reservatório de vitamina A no corpo humano (ANDRADE, 2005). Durante o desenvolvimento da fibrose hepática, todas as células hepáticas sofrem alterações específicas. Os hepatócitos são lesionados e sofrem apoptose. O macrófago residente no fígado, a célula de Kupffer, é ativado e produz uma grande variedade de quimiocinas e citocinas, que são as responsáveis pelo recrutamento dos linfócitos que irão infiltrar no fígado lesionado e contribuirão para o desencadeamento da inflamação. Consequentemente, as células estreladas de lto, que no fígado normal estão em repouso, após várias lesões, sofrem alterações fenotípicas e, dessa forma, são ativadas (BRENNER, 2009; ÖSTERREICHER; ÖSTERREICHER; TRAUNER, 2011); isto é, diferenciam-se sob ação de citocinas fibrogênicas (TNF- $\alpha$, TGF- $\beta$, PDGF e outras) em miofibroblasto e fibroblasto, por intermédio da síntese dos elementos da matriz: colágenos, elastina, proteoglicanas e proteínas de constituição (ANDRADE, 2005). 
As citocinas são proteínas secretadas pelas células da imunidade natural e adquirida, modulando a função de células vizinhas. As citocinas são importantes no controle das células do sistema imune e de outros sistemas, exercendo diversos efeitos em várias células, ou até em um mesmo tipo celular. Elas possuem a capacidade de causar mudanças na proliferação, diferenciação e migração celular (ABBAS; LITCHMAN; PILLAI, 2008). Algumas citocinas podem agir no controle da expressão dos miofibroblastos, inibindo-os, como o interferon-gama (IFN- $\gamma$ ), interferon-alfa (IFN- $\alpha$ ), fator de crescimento dos hepatócitos (HGF) e IL-10, ou ativando-os, como ocorre com o fator de crescimento de necrose tumoral (TNF- $\alpha$ ) (LOUIS et al., 1998).

O TNF- $\alpha$ é uma citocina produzida, principalmente, por macrófagos, porém células Natural Killer (NK), células T e mastócitos também são capazes de produzir essa citocina e tem, como principal ação biológica, de estimular as células do endotélio vascular a produzirem moléculas de adesão que facilitem a adesão dos neutrófilos (BORGES, 2008). O TNF- $\alpha$, estimula as células hepáticas a produzirem proteínas séricas; dentre elas, o fibrinogênio e a proteína C reativa; a combinação dessas substâncias resulta na resposta aguda a um processo inflamatório (ABBAS; LITCHMAN; PILLAI, 2008).

A interleucina-6 (IL-6) é uma citocina secretada por diferentes células, como macrófagos, linfócitos $T$ e fibroblastos. Durante a fase inicial da regeneração hepática, são secretadas pelas células de Kupffer, estimulando os hepatócitos a sintetizarem proteínas, que controlam a fase aguda da inflamação (GEISTERFER et al., 1993). Durante a lesão crônica do fígado, como a induzida pela LDB, a IL-6, além de atuar na manutenção dos hepatócitos, é capaz de estimular a síntese de DNA nas células epiteliais biliares, assim como, inibir a apoptose dessas células, contribuindo, assim, para a integridade e expansão da árvore biliar (LIU et al., 1998; EZURE et al., 2000). Essas mesmas células, assim como as células de Kupffer, também são capazes de produzir TNF- $\alpha$ e TNF- $\beta$, fatores que ativam os miofibroblastos e inibem a sua apoptose, contribuindo para a contínua e excessiva deposição de matriz extracelular por essas células, o que distorce, gradualmente, a arquitetura do parênquima hepático (SAILE et al., 1999; GRESSNER et al., 2002).

A interleucina-10 (IL-10) é uma citocina anti-inflamatória, secretada por diversas populações celulares, incluindo linfócitos $T$ auxiliares, linfócitos $B$, monócitos, macrófagos. $O$ efeito protetor da IL-10 foi verificado em diferentes modelos experimentais, dentre eles, a fibrose induzida pela LDB e pela droga tetracloreto de carbono $\left(\mathrm{CCl}_{4}\right)$ (LOUIS et al., 1998). Segundo Leija, Reyes e Rodriguez (2007) e Abbas, Litchman e Pillai (2008), a regulação e supressão da inflamação ocorre por meio da inibição de citocinas pró-inflamatórias, como IL$1 \beta$, IL-1 $\alpha$, IL-2, IL-6 e TNF- $\alpha$, sendo este último a citocina-"chave" no desenvolvimento da hepatotoxidade. Wang et al. (1998) reportaram que, tanto in vitro, como in vivo, as células estreladas ativadas (miofibroblastos) isoladas de fígados de ratos, após 10 dias da LDB, foram capazes de secretar grande quantidade de IL-10, a qual, por mecanismo autócrino, reduzia a produção de colágeno e aumentava a produção de enzimas colagenases, contribuindo para o equilíbrio entre deposição e degradação da matriz extracelular.

Segundo Leija, Reyes e Rodriguez (2007), apesar das pesquisas terem permitido 
avanços no entendimento dos mecanismos celulares e moleculares envolvidos no processo da fibrose hepática, e sua progressão para a cirrose hepática, esses conhecimentos tiveram muito pouco efeito no desenvolvimento de novas drogas para as doenças crônicas do fígado.

\section{OBJETIVO}

Analisar, quantitativamente, o perfil das citocinas pró-inflamatórias (IL-6 e TNF- $\alpha$ ) e antiinflamatória (IL-10), no fígado de ratos, com diferentes graus de fibrose, induzida pela ligadura do ducto biliar.

\section{METODOLOGIA}

\subsection{Animais}

Foram usados, neste estudo, 20 ratos machos albinos, da raça Wistar, com peso aproximado de 200 a 250g. Os animais foram mantidos no Biotério de Passagem do Instituto de Pesquisa \& Desenvolvimento (IP\&D), da Universidade do Vale do Paraíba, em gaiolas adequadas, contendo quatro animais, em cada gaiola, com água e ração autoclavada, com um ciclo de 12 horas de claridade e 12 horas de escuridão e, em temperatura ambiente, constante de $22 \pm 2^{\circ} \mathrm{C}$. A limpeza das gaiolas foi realizada três vezes por semana no mesmo horário.

Depois de uma semana de aclimatização, os animais foram, aleatoriamente, divididos em três grupos: 1) grupo LDB $2 s(n=4)$, no qual os animais foram submetidos ao procedimento cirúrgico da ligadura do ducto biliar e sacrificados após 2 semanas da ligadura; 2) grupo LDB 4s $(n=8)$, em que os animais foram submetidos à ligadura do ducto biliar e sacrificados após 4 semanas da ligadura; e 3) grupo LDB $6 s(n=8)$, em que os animais foram submetidos à ligadura do ducto biliar e sacrificados após 6 semanas da mesma.

\subsection{Modelo experimental para indução da fibrose hepática - Ligadura do Ducto Biliar (LDB)}

Os procedimentos cirúrgicos foram realizados pelo mesmo cirurgião e as técnicas, totalmente assépticas. Os animais foram anestesiados com isoflorano a 3\%, por via inalatória, em câmara própria. Para controlar as quantidades administradas de anestésico, foi utilizado um vaporizador calibrado. Quando o animal estava imóvel e perdeu o reflexo de endireitamento, ele foi pesado em uma balança de precisão e, depois, foi posicionado em decúbito dorsal e imobilizado em mesa cirúrgica. A partir desse momento, a anestesia foi mantida pela inalação de mistura de $\mathrm{O}_{2}$ e isoflorano a 2,5\%. A intervenção cirúrgica iniciou com tricotomia e desinfecção da região abdominal, seguida de uma incisão na linha mediana e exposição do ducto biliar comum, o qual foi duplamente ligado com fio de sutura Seda 4-0 (Ethicon - Johnson \& Johnson). A primeira ligadura foi realizada da junção dos ductos 
hepáticos e a segunda ligadura foi feita acima da entrada do ducto pancreático, conforme relatado por Chen et al. (2009). O ducto biliar comum foi, então, seccionado entre as ligaduras. A incisão abdominal foi fechada, em dois planos, com fio de sutura seda 4-0 e 3-0 (Ethicon Johnson \& Johnson). Dessa forma, os animais tiveram total e permanente obstrução biliar.

\subsection{Eutanásia dos animais e Coleta das amostras biológicas}

Após 2, 4 e 6 semanas da indução da fibrose, os animais foram pesados e anestesiados para a remoção do fígado e realização do preparo do homogeneizado e as análises das citocinas pró-inflamatórias e anti-inflamatórias, utilizando a técnica de ELISA. Os animais foram eutanasiados com overdose do mesmo anestésico isoflorano.

\subsection{Preparo das amostras de fígado para a dosagem de citocinas}

Após a retirada do fígado, este foi colocado numa placa de Petri e pesado. Em seguida, o fígado foi lavado com solução fisiológica e os lobos caudados foram separados dos demais lobos. Os lobos caudados foram colocados em uma placa de Petri limpa e pesados. Posteriormente, esses lobos foram cortados em pedaços menores, com peso aproximado de $250 \mathrm{mg}$. Em um almofariz com nitrogênio líquido, o tecido foi triturado, manualmente, com auxílio do pistilo, até ficar totalmente pulverizado. Em seguida, foi adicionado 2,5 $\mathrm{mL}$ de PBS, contendo $5 \%$ de soro de cabra e $10 \mu \mathrm{L} / \mathrm{mL}$ de inibidor de protease (Sigma P8340). Após homogeneização completa, o material obtido foi centrifugado a $4^{\circ} \mathrm{C}$ por 30 minutos a 10.000 rpm, por 3 vezes. O sobrenadante foi, então, aliquotado e estocado a $-70^{\circ} \mathrm{C}$ até a dosagem de citocinas.

\subsection{Dosagem das citocinas por ELISA}

As citocinas pró-inflamatórias (IL-6 e TNF- $\alpha$ ), e anti-inflamatória (IL-10) foram dosadas por meio do método Elisa, do tipo sanduíche, segundo as orientações do fabricante (Invitrogen ${ }^{\mathrm{TM}}$ ). Foi utilizado um anticorpo monoclonal de captura, fixo à placa de 96 poços, outro anticorpo monoclonal de detecção biotinilado, a enzima peroxidase (HRP) e estreptavidina e o peróxido de hidrogênio com tetrametilbenzidina (TMB) como revelador, de acordo com as orientações do fabricante (Invitrogen ${ }^{\mathrm{TM}}$ ). A citocina recombinante foi diluída para a curva padrão. As amostras foram quantificadas em espectrofotômetro a $450 \mathrm{~nm}$ (Quant - Biotek $\left.{ }^{\circledR}\right)$.

\subsection{Análise Estatística}

Os dados obtidos das dosagens das citocinas pró e anti-inflamatórias foram analisados, estatisticamente, por intermédio do programa GraphPad InStat 3.0, sendo $p<0.05$ considerado 
diferença significativa. As diferenças entre os grupos foram analisadas pela análise de variância (ANOVA) fator único, seguido pelo teste de comparações múltiplas de Tukey. Para o TNF- $\alpha$, foi utilizado o teste $t$ de Student, para a comparação de 2 amostras independentes.

\section{RESULTADOS}

\subsection{Macroscopia}

Após a eutanásia dos animais, o fígado foi analisado, macroscopicamente, observandose diferenças em relação ao aspecto macroscópico do fígado dos animais submetidos à LDB, após 2, 4 e 6 semanas, como mostra a Figura 1.

O fígado dos ratos, após 2 semanas da LDB (Figura 1A), apresentou superfície levemente rugosa e opaca, com coloração vermelha clara e consistência endurecida e o tamanho um pouco aumentado.

O fígado dos animais de 4 e 6 semanas, após a LDB (Figura 1B e 1C), apresentou superfície rugosa, opaca com coloração verde-amarelada e consistência endurecida. Também, apresentou um aumento no tamanho do fígado, quando comparados aos animais eutanasiados após 2 semanas de LDB.

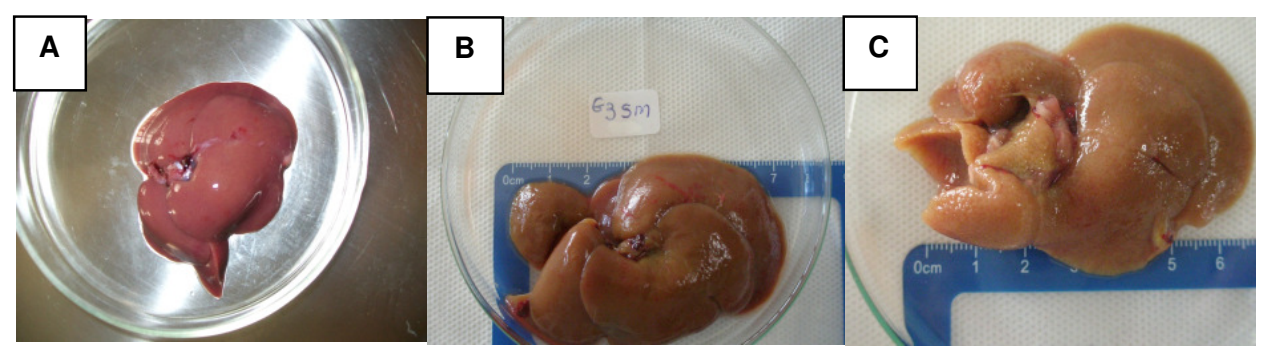

Figura 1 - A: Fígado após 2 semanas de LDB; B: Fígado com 4 semanas após LDB; C: Fígado com 6 semanas após LDB.

\subsection{Dosagem das citocinas}

Os resultados das dosagens das citocinas pró e anti-inflamatórias estão apresentados nas Figuras 2, 3 e 4. 


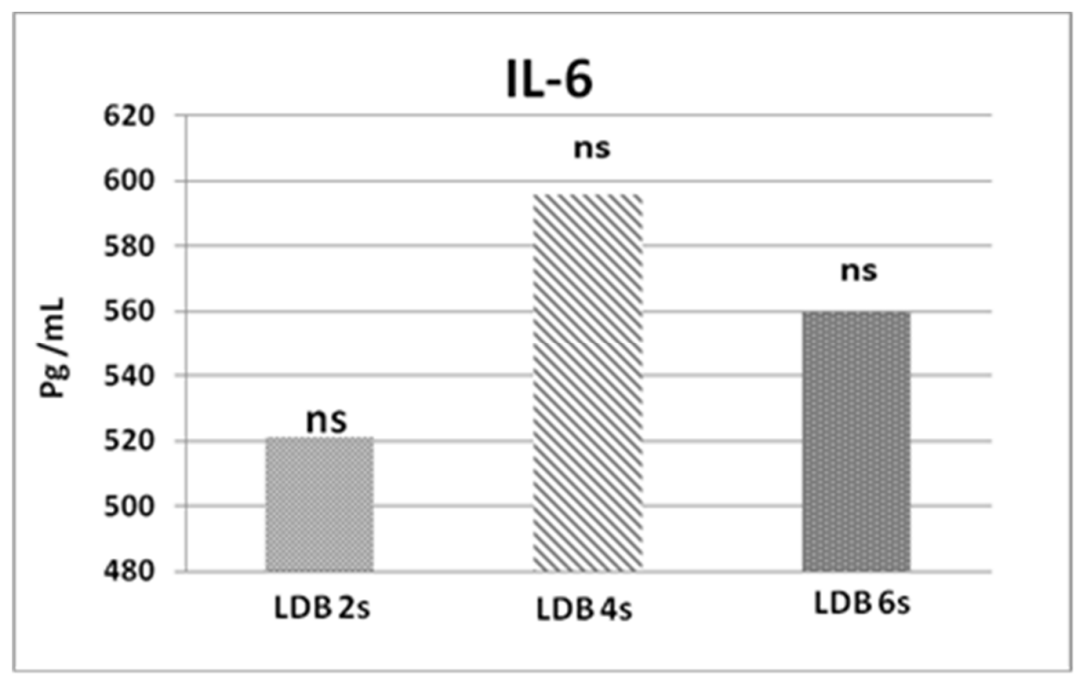

Figura 2 - Médias da citocina pró-inflamatória IL-6 no fígado dos animais após 2, 4 e 6 semanas da indução da fibrose, nos grupos experimentais LDB2s, LDB4s e LDB6s, respectivamente. ns = não significativo.

Os valores médios da citocina IL-6 não apresentaram diferenças significativas entre os grupos estudados. Houve um discreto aumento de IL-6 da $2^{\underline{a}}$ para $4^{\mathrm{a}}$ semana, e uma discreta diminuição da $4^{\mathrm{a}}$ para a $6^{\mathrm{a}}$ semana.

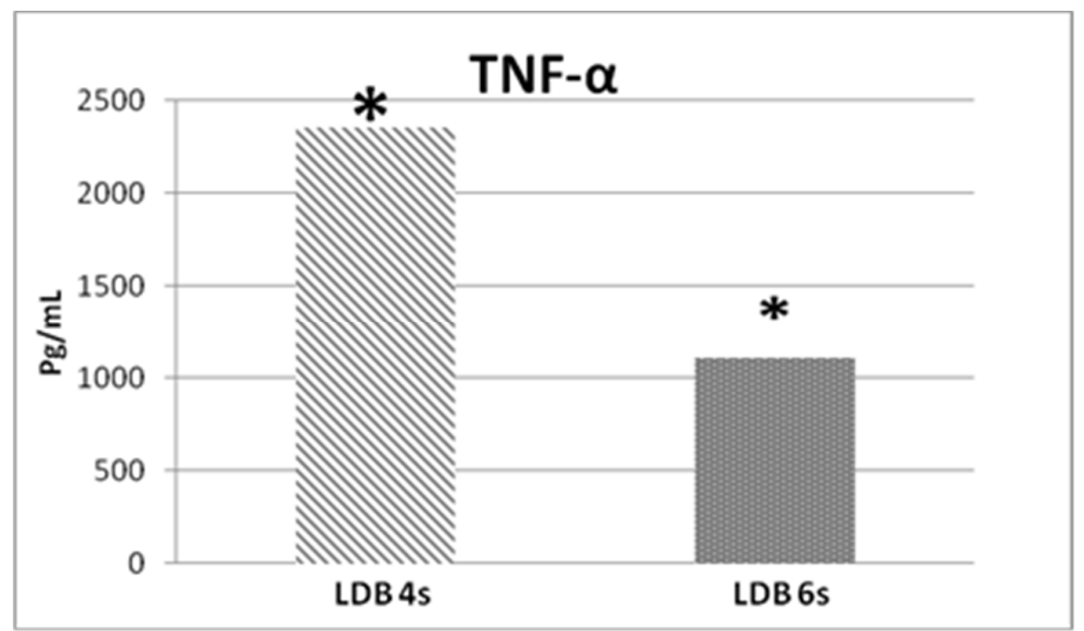

Figura 3 - Médias da citocina pró-inflamatória TNF- $\alpha$ no fígado dos animais após 4 e 6 semanas da indução da fibrose, nos grupos experimentais LDB4s e LDB6s, respectivamente.

* $p<0,05$ (LDB4s x LDB6s).

A média de TNF- $\alpha$ na 4aㅗ semana após LDB, foi elevada e de, aproximadamente, 2400 $\mathrm{pg} / \mathrm{mL}$, enquanto que, na $6^{\mathrm{a}}$ semana, a média diminuiu significativamente e atingiu valores de, aproximadamente, $1000 \mathrm{pg} / \mathrm{mL}$. O comportamento do TNF- $\alpha$, nos grupos tratados, foi bastante diferente do observado para IL-6. 


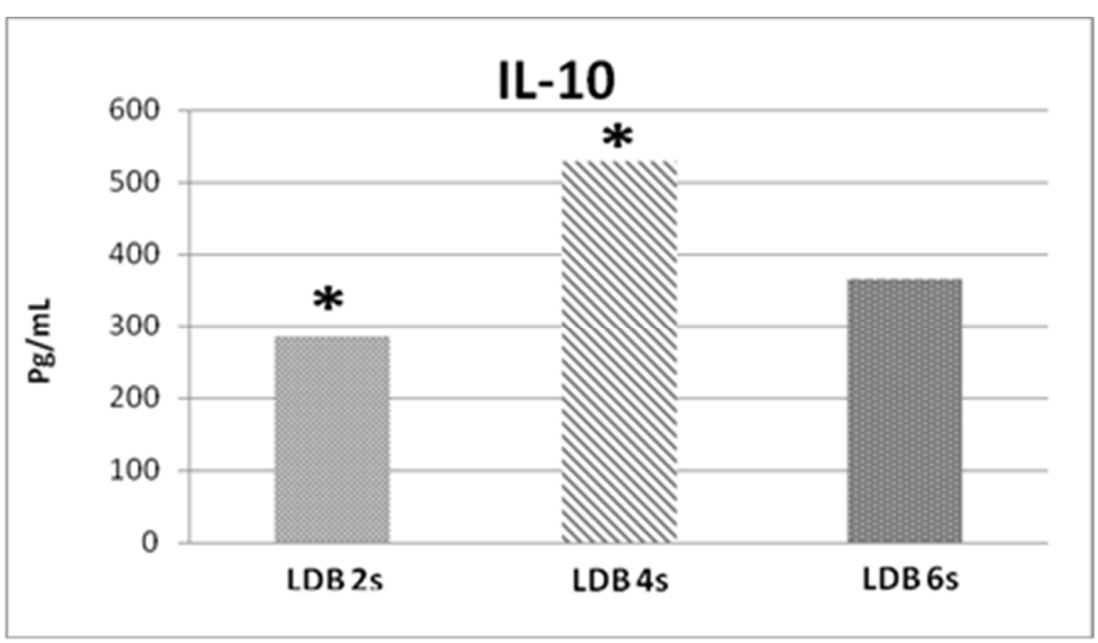

Figura 4 - Médias da citocina anti-inflamatória IL-10 no fígado dos animais após 2, 4 e 6 semanas da indução da fibrose, nos grupos experimentais LDB2s, LDB4s e LDB6s, respectivamente. ${ }^{*} p<0,05$ (LDB2s x LDB4s).

A média da citocina anti-inflamatória IL-10 foi de, aproximadamente, $290 \mathrm{pg} / \mathrm{mL}$ após 2 semanas de LDB. Após 4 semanas, a concentração dessa citocina elevou-se significativamente ( $520 \mathrm{pg} / \mathrm{mL})$. Já, após 6 semanas, o valor da IL-10 diminuiu, entretanto permanecendo acima dos valores encontrados no grupo LDB2s.

\section{DISCUSSÃO}

De acordo com os resultados obtidos após a análise macroscópica notou-se que houve alterações na pigmentação, tamanho e aspecto do fígado. Segundo Quaresma et al. (2003), a obstrução extra-hepática acarreta alterações que modificam o aspecto macroscópico do fígado, em relação à pigmentação do órgão, mudando de vermelho escuro para verdeamarelada, e a sua superfície, tornando-se endurecida e rugosa. De acordo com Österreicher, Österreicher e Trauner (2011), as lesões hepáticas provocam um crescimento na proliferação de ductos biliares, o que acarreta no aumento do tamanho do fígado. O endurecimento do fígado ocorre, pois, na fibrose hepática, as células estreladas de Ito estão ativadas, sendo estas as responsáveis pela maior produção de colágeno na maioria das doenças hepáticas.

Segundo Tsukamoto (1999), as citocinas e fatores de crescimento constituem a principal classe de mediadores envolvidos na fibrogênese, tanto durante o processo normal de reparo, quanto na deposição excessiva de colágeno, o que induz a presença de cicatrizes, seja no fígado ou em qualquer outra doença fibroproliferativa, como, por exemplo, a fibrose pulmonar ou artrites.

Em nosso modelo experimental, a análise do perfil das citocinas, durante a fibrose biliar, demonstrou ser a 4를 semana após a LDB, o auge da inflamação, o que está de acordo aos achados de Schierwagen et al. (2013). Esse estudo relatou que o período entre a $1^{\underline{a}}$ e a $4^{\underline{a}}$ 
semana após a LDB corresponde às fases inicial e intermediária da fibrose, fases em que a inflamação é maior do que o acúmulo excessivo de matrix extracelular ( fibrose), o contrário do período entre a $4^{\underline{a}}$ e a $6^{\underline{a}}$ semana, o qual reflete a fase avançada da fibrose, fase na qual a fibrose se sobrepõe à inflamação. O auge da inflamação, também, é comprovado em nosso estudo pela elevação das citocinas pró-inflamatórias, IL-6 e TNF- $\alpha$, na 4ª semana após a LDB, especialmente a citocina TNF- $\alpha$ (Figuras 2 e 3). Estes resultados estão de acordo com Fernandez-Martinez et al. (2006) e Tahan et al. (2010), os quais também verificaram, em ratos, que 4 semanas de obstrução do ducto biliar elevam, tanto as citocinas próinflamatórias, quanto a citocina anti-inflamatória, IL-10.

Embora o aumento e dimuição de IL-6 não seja significativo (Figura 2), a média da citocina TNF- $\alpha$ foi, estatisticamente, significativa após 4 e 6 semanas da LDB (Figura 3), colaborando para uma inflamação severa na $4^{\underline{a}}$ semana, e sugerindo ser o TNF- $\alpha$ a citocina mais atuante durante as fases inicial e intermediária da fibrose biliar, quando comparada com a IL-6. Essa sugestão pode ser suportada pelo fato do TNF- $\alpha$ ser um dos principais componentes produzido em resposta a uma injúria hepática (LEIJA; REYS; RODRIGUEZ, 2007) por células que predominam na fase inicial ou fase inflamatória da fibrose, como os monócitos e células de Kupffer (BORGES, 2008) e, também, por células epiteliais biliares (TSUKAMOTO, 1999). O fato da citocina IL-6 não mostrar diferença significativa entre os grupos experimentais do nosso estudo indica que ela atua de forma mais ou menos contínua durante todas as fases da fibrose biliar. Esse fato pode ser suportando por FernandezMartinez et al. (2006), o qual, também, observou que a IL-6 não apresenta diferença significativa entre os grupos sem e com fibrose na $4^{\text {a }}$ semana após a LDB, além da sua diminuição na fase avançada da fibrose, argumentando que a IL-6 tende a diminuir, moderadamente, na cirrose hepática.

Segundo Liu et al. (1998) e Ezure et al. (2000), durante a lesão crônica do fígado, como a induzida pela LDB, a IL-6, estimula a síntese de DNA nas células epiteliais dos ductos biliares, assim como inibe a apoptose dessas células, contribuindo para a integridade e expansão da árvore biliar. Por outro lado, as células epiteliais biliares, quando estimuladas por outras citocinas pró-inflamatórias, podem, também, produzir e secretar IL-6, que atua como um fator de crescimento autócrino, intensificando a proliferação da árvore biliar (MATSUMOTO et al., 1994; YASOSHIMA et al., 1998; YOKOMURO et al., 2000). Além dessas funções, a IL-6 sintetizada pelos ductos biliares, ativa os miofibroblastos, os quais, na fibrose biliar, estão em íntimo contato com os ductos em expansão (DRANOFF; WELLS, 2010; ÖSTERREICHER; ÖSTERREICHER; TRAUNER, 2011). Adicionalmente, segundo Saile et al., 1999; GRESSNER et al., 2002), os ductos biliares, também, produzem TNF- $\alpha$ e TGF- $\beta$, os quais contribuem para a ativação dos miofibroblastos e à contínua e excessiva deposição de matriz extracelular por essas células, distorcendo, gradualmente, a arquitetura do parênquima hepático. Sant'Anna et al. (2011), utilizando o mesmo modelo experimental que o nosso estudo, porém avaliando os aspectos microscópicos da fibrose, ao invés das citocinas, demonstraram que, da $2^{\underline{a}}$ para a $4^{a}$ semana após a LDB, o número de ductos biliares, assim como o de miofibroblastos aumentou significativamente. Juntos, os estudos 
acima suportam a hipótese de que o aumento das citocinas pró-inflamatórias IL-6 e TNF- $\alpha$ verificado em nosso estudo (Figuras 2 e 3), pode estar fortemente relacionado com o papel das mesmas na expansão dos ductos biliares e ativação dos miofibroblastos, sinais microscópicos característicos da fibrose biliar.

A IL-10 é uma citocina anti-inflamatória importante na regulação da resposta inflamatória, por meio de vários mecanismos, incluindo a redução da expressão do antígeno de leucócito humano II (HLA classe II), diminuição da secreção de IL-2 pelas células T, e redução de IL-1 $\alpha$, IL-1 $\beta$, TNF- $\alpha$ e IL-8 pelos monócitos e macrófagos ativados durante a inflamação (LEIJA; REYES; RODRIGUEZ, 2007). Fernandez-Martinez et al. (2006), estudando a fibrose biliar, após 4 semanas da LDB, verificaram que o aumento da IL-10, durante a fibrose, foi responsável pela redução da citocina pró-inflamatória, IFN- $\gamma$ no mesmo grupo, indicando que, também na fibrose hepática, o aumento das citocinas pró-inflamatórias é equilibrado pelo aumento das anti-inflamatórias. Assim também, Louis et al. (1998) verificaram que a IL-10 diminuiu, significativamente, a citocina TNF- $\alpha$ e, moderadamente, a IL-6, confirmando ser a IL-10 anti-inflamatória e anti-fibrótica, uma vez que, também encontraram diminuição no TGF- $\beta$, importante citocina na perpetuação da fibrose hepática, por manter a excessiva deposição de matriz extracelular. Baseados nesses estudos, podemos vincular a diminuição do TNF- $\alpha$ da 4⿳亠丷a para a 6ª semana (Figura 3 ) ao fato da produção elevada de IL-10, também na $4^{\text {a }}$ semana (Figura 4), provavelmente para controlar a exacerbada produção de TNF- $\alpha$, culminando, assim, com a redução desta última na $6^{\mathbf{a}}$ semana. Em seguida, a IL-10 também reduziu, moderadamente, e segundo Fernandez-Martinez et al. (2006), esta redução pode ser a razão pela qual seus efeitos anti-inflamatório e antifibrótico não são capazes de reduzir a fibrose severa, mas apenas modularem a fase inflamatória que antecede àquela.

Assim, acreditamos que o nosso estudo poderá auxiliar para aumentar o entendimento do complexo mecanismo de regulação das citocinas, o qual permitirá o desenvolvimento de terapias que atuem, especificamente, nas células e/ou nas citocinas produzidas por elas, na tentativa de estabelecer uma terapia preventiva ou de redução da progressão da fibrose/cirrose biliar.

\section{CONCLUSÃO}

Dentro das condições experimentais deste trabalho, com base nos resultados obtidos, conclui-se que o TNF é a principal citocina na progessão da fibrose biliar, principalmente durante sua fase intermediária. Ao mesmo tempo, a IL-10 atua nessa fase, limitando a produção da citocina pró-inflamatória TNF- $\alpha$, na tentativa de um controle endógeno da progressão da doença. 


\section{REFERÊNCIAS}

ABBAS, A. K.; LITCHMAN A. H.; PILLAI, F. Citocinas. In: ABBAS, A. K.; LITCHMAN A. H.; PILLAI, F. Imunologia celular e molecular. Rio de Janeiro: Elsevier, 2008. pp. 267-288.

ANDRADE, Z. A. Regressão da fibrose hepática. Revista da Sociedade Brasileira de Medicina Tropical, v. 38, n. 6, pp. 514-520, 2005.

BATALLER, R.; BRENNER, D. A. Liver fibrosis. Journal of Clinical Investigation, v. 115, pp. 209-218, 2005.

BORGES, R. A. O. Avaliação da produção de citocinas em camundongos cubmetidos à irradiação laser e ftalocianina de silício. 2008. 56f. Dissertação (Mestrado em Engenharia Biomédica) - Instituto de Pesquisa e Desenvolvimento, Universidade do Vale do Paraíba, São José dos Campos, 2008.

BRENNER, D. A. Molecular pathogenesis of liver fibrosis. Transactions of the American Clinical and Climatological Association, v. 120, pp. 361-368, 2009.

CHEN, W. Y.; CHEN, C. J.; LIAO, J. W.; MAO, F. C. Chromium attenuates hepatic damage I a rat model of chronic cholestasis. Life Sciences, v. 84, pp. 606-614, 2009.

DRANOFF, J. A.; WELLS, R. G. Portal fibroblasts: underappreciated mediators of biliary fibrosis. Hepatology, v. 51, pp. 1438-1444, 2010.

EZURE, T. et al. The development and compensation of biliary cirrhosis in interleukin-6deficient mice. Am. J. Pathol., v. 156, pp. 1627-1639, 2000.

FERNÁNDEZ-MARTINEZ, E. et al. Chronic bile duct obstruction induces changes in plasma and hepatic levels of cytokines and nitric oxide in the rat. Experimental and Toxicologic Pathology, v. 58, pp. 49-58, 2006.

GEISTERFER, M. et al. Regulation of IL-6 and the hepatic IL-6 receptor in acute inflammation in vivo. Cytokine, v. 5, pp. 1-7, 1993.

GRESSNER, A. M. et al. Roles of TGF-beta in hepatic fibrosis. Frontiers in Bioscience, v. 7, pp. 793-807, 2002.

HENDERSON, N. C.; FORBES, S. J. Hepatic fibrogenesis: from within and outwith. Toxicology, v. 254, pp. 130-135, 2008.

LEIJA, A.; REYES, J.; RODRÍGUEZ, L. Hepatic stellate cells are a major component of liver fibrosis and a target for the treatment of chronic liver disease. Biotecnología Aplicada, v. 24, pp. 19-25, 2007.

LI, M. K.; CRAWFORD, J. M. The pathology of cholestasis. Seminars in liver disease, v. 24, pp. 21-42, 2004.

LIU, Z. et al. Interleukin-6, hepatocyte growth factor, and their receptors in biliary epithelial cells during a type I ductular reaction in mice: interactions between the periductal inflammatory and stromal cells and the biliary epithelium. Hepatology, v. 28, pp. 1260-1268, 1998. 
LOUIS, H. et al. Interleukin-10 controls neutrophilic infiltration, hepatic proliferation, and liver fibrosis induced by carbon tetrachloride in mice. Hepatology, v. 28, n. 6, pp. 1607-15, 1998.

MATSUMOTO, K. et al. Human biliary epithelial cells secrete and respond to cytokines and hepatocyte growth factors in vitro: interleukin-6, hepatocyte growth factor and epidermal growth factor promote DNA synthesis in vitro. Hepatology, v. 20, pp. 376-382, 1994.

NADER, L. A.; MATTOS, A. A.; BASTOS, G. A. N. Burden of liver disease in Brazil. Liver International, v. 34, pp. 844-849, 2014.

ÖSTERREICHER, M. P.; ÖSTERREICHER, C. H.; TRAUNER, M. Fibrosis in autoimmune and cholestatic liver disease. Best Practice Research Clinical Gastroenterology, v. 25, pp. 245258, 2011.

QUARESMA, A. B. et al. Estudo histológico do fígado de ratos após ligadura do ducto hepático direito. Arquivos Catarinenses de Medicina, v. 32, n. 3, pp. 28-36, 2003.

SAILE, B. et al. Transforming growth factor beta and tumor necrosis factor alpha inhibit both apoptosis and proliferation of activated rat hepatic stellate cells. Hepatology, v. 30, pp. 196202, 1999.

SANT'ANNA, L. B. et al. Amniotic membrane application reduces liver fibrosis in a Bile Duct Ligation model. Cell Transplantation, v. 20, p. 441-453, 2011.

SCHIERWAGEN, R.; LEEMING, D. J.; KLEIN, S.; GRANZOW, M.; NIELSEN, M. J.; SAUERBRUCH, T.; KRAG, A.; KARSDAL, M. A.; TREBICKA, J. Serum markers on the extracellular matrix remodeling reflect antifibrotic therapy in bile duct ligated rats. Frontiers in Physiology, v. 4, pp. 1-9, 2013.

SCHUTTE, K.; BORNSCHEIN, J.; MALFERTHEINER, P. Hepatocellular carcinomaepidemiological trends and risk factors. Digestive Diseases, v. 27, pp. 80-92, 2009.

TAHAN, G. et al. Melatonin ameliorates liver fibrosis induced by bile-duct ligation in rats. Canadian Journal of Surgery, v. 53, n. 5, pp. 313-318, 2010.

TSUKAMOTO, H. Cytokine regulation of hepatic stellate cells in liver fibrosis. Alcoholism: Clinical and Experimental Research, v. 23, n. 5, pp. 911-916, 1999.

WANG, S. C. et al. Expression of interleukin-10 by in vitro and in vivo activated hepatic stellate cells. Journal of Biological Chemistry, v. 273, pp. 302-308, 1998.

YASOHIMA, M. et al. Increased expression of interleukin-6 and tumor necrosis factor-alpha in pathologic biliary epithelial cells: in situ and culture study. Laboratory Investigation, v. 78, pp. 89-100, 1998.

YOKOMURO, S. et al. The effect of interleukin-6 (IL-6)/gp130 signaling on biliary epithelial cell growth, in vitro. Cytokine, v. 12, n. 6, pp. 727-30, 2000. 